\title{
UM PENSAMENTO MAIS LUIZGONZAGUIANO: MÚSICA E SONHOS DE UMA ESCOLA DE COMUNIDADE RURAL
}

Zacarias Marinho ${ }^{*}$ )

\section{INTRODUÇÃO}

Este artigo advém de um recorte de uma pesquisa que se debruçou sobre os aspectos de recontextualização de programas e projetos, como parte do que denominei de política de programas/projetos, numa escola de comunidade rural e na comunidade onde está localizada a escola. O recorte, a ser considerado aqui, trata de um aspecto da relação comunidade/escola, por meio da atuação da política Programa Mais Cultura Nas Escolas (PMCE). O artigo tem, assim, como objetivo compreender o desenvolvimento da proposta elaborada pela escola e pelo parceiro artístico (representando a comunidade), que tem como referência edital próprio do Ministério da Cultura. Para isso, analiso as construções discursivas em relação à política em tela, a qual fazia parte de um pacote que denominei de Políticas Mais e que, além de tal programa, havia outros em desenvolvimento na escola, como era o caso do Programa Mais Educação, por exemplo.

A pesquisa tem como objetivo geral analisar como políticas de programas/projetos educacionais influenciam a recontextualização do currículo na escola, tendo como lócus uma escola de Ensino Fundamental situada numa comunidade rural no Município de Mossoró-RN. A investigação envolveu sujeitos escolares e comunitários, ganhando um desenho de pesquisa de cunho etnográfico, a qual se distingue como "um procedimento de pesquisa que se dirige a pequenas populações, em desenhos de pesquisas que não exigem um tão alto grau de formalidade, mas que pretendem priorizar os contatos pessoais, as relações face a face”. (TURA; SILVA, 2010, p. 72). Contribuiu ainda para essa opção de pesquisa a compreensão de que "[...] cada escola é uma unidade de vida e trabalho, que está inserida em um conjunto complexo de situações concretas, repletas de estratégias pessoais de sobrevivência, contextos históricos e especificidades regionais e locais [...]" (TURA, 2000, p. 11).

Por conta dessa opção metodológica, trabalhei com base em Lourdes Tura - Tura (2000) e Tura e Silva (2010) - que amparam as incursões de pesquisa no espaço-tempo da escola e com a

\footnotetext{
${ }^{(*)}$ Professor Adjunto IV da Universidade do Estado do Rio Grande do Norte. E-mail: zacariasmarinho@ yahoo.com.br.
} 
abordagem do Ciclo Contínuo de Política1, de Bowe, Ball e Gold (1992); Ball (1994), apoiando-me também em Mainardes (2006; 2007); Lopes e Macedo (2011). Dessa forma, procurei estabelecer as relações que permeiam os vários contextos nos quais as políticas educacionais estão imersas e imbricadas pelos discursos que circulam entre eles, interconectando macro e micro contextos, como é o caso da política de programas/projetos presente na escola. Apropriei-me, assim, de duas premissas utilizadas por Stephen Ball (TURA et al. 2012), de que a escola não é independente do seu entorno, mas também não é somente uma adaptação a ele.

Com esse referencial teórico-metodológico procurei apreender o cotidiano da escola, compreendendo que para além do local se tem ali a presença de outros contextos. Assim, o Contexto da Prática foi considerado como um entrecontexto, o que possibilitou as reflexões e a análise das especificidades da política de currículo configurada em programas/projetos educacionais na escola campo de pesquisa e sua recontextualização, considerando as múltiplas negociações que se dão para que a política seja promulgada no espaço da escola e da comunidade.

A expressão "um pensamento mais luizgonzaguiano", que uso para dar título a este artigo, foi cunhada pelo artista2 coordenador do programa na proposta local, em entrevista feita com ele na comunidade rural onde está localizada a Escola Caminhos3. Este, de acordo com a estrutura do PMCE, era identificado pela categoria parceiro artístico4, sendo o responsável pelo desenvolvimento das atividades, que de acordo com a proposta aprovada para aquela escola, resumidamente, era a de ensinar aos alunos e alunas inscritos(as) a tocar e cantar músicas da MPB, relacionadas na referida proposta.

Entrevistei, ainda, professores(as), alunos(as) e um membro da equipe pedagógica da escola. Esses sujeitos5, de forma direta ou indireta, envolveram-se na atuação da política PMCE e, por suas entrevistas, contribuíram para compreendermos e analisarmos melhor a referida política.

\footnotetext{
${ }^{1}$ Utilizo do Ciclo Contínuo de Política, para fins de análise, os Contextos de Influência, de Produção de Textos e da Prática. O primeiro se refere à diversidade de sujeitos que contribuem com suas influências para que a política seja sistematizada e anunciada pelos Órgãos de Estado; o segundo diz respeito à representação da política nas mais diversas formas de discursos e o terceiro se refere ao local onde a política é desenvolvida pelos sujeitos em sua atuação sobre a política. (Ver BOWE, BALL e GOLD, 1992; MAINARDES, 2006, 2007; LOPES e MACEDO, 2011).

${ }^{2} \mathrm{O}$ parceiro artístico tem trabalhos autorais, incluindo dois CDs gravados com recursos próprios, participou de vários festivais, foi premiado em alguns; desenvolve sua arte em locais públicos e privados quando é convidado ou por iniciativa própria com outros músicos.

${ }^{3}$ Nome fictício que dei a escola para fins de publicação.

${ }^{4}$ Designação dos atores parceiros da escola na elaboração e execução do plano contemplado pelo programa.

${ }^{5}$ Os alunos e alunas entrevistados(as) têm entre 13 e 16 anos de idade e são de turmas de $6^{\circ}$ ao $9^{\circ}$ ano do Ensino Fundamental; os professores(as) atuam em diferentes disciplinas e alguns estavam na escola há mais de 10 anos,
} 
Foi importante também a observação participante ao longo de dois anos e meio no interior do espaço escolar, bem como o registro em diário de campo. Essa estratégia possibilitou ao investigador encontrar elementos de tessitura, os quais só foram possíveis captar, na trama do cotidiano, devido ao olhar de fora, de estranhamento de quem não está envolvido diretamente no enredo da escola. É ver nas "piscadelas" como se referiu Geertz (2008), para explicar o fato do etnógrafo necessitar observar pequenos detalhes para compreender o fenômeno sobre o qual está se debruçando para fins de análise. A Escola Caminhos foi o cenário que a política analisada foi apreendida em sua recontextualização e atuação.

Além dessa parte introdutória, mais três partes compõem o artigo. $\mathrm{Na}$ primeira, abordo o PMCE, problematizando os sentidos presentes em sua proposta como política curricular, significada como política de cultura, bem como os Contextos de Influência e de Produção de Texto que envolvem essa política.

Na segunda parte, abordo o Contexto da Prática, que a exemplo dos outros contextos do Ciclo Contínuo de Política, contém e está contido nos demais, configurando-se como um híbrido ou um entrecontexto, termo com o qual faço referência ao fato de Ball (2009) dizer que esses contextos se aninham uns com os outros.

Por fim, teço minhas considerações finais sintetizando as principais ideias aqui abordadas e abrindo caminhos para discussões que ajudem a problematizarmos as Políticas Mais, as políticas de programas/projetos que se desenvolvem nas escolas e, especialmente, a música como objeto de aprendizagem e os sons enquanto linguagem apropriada pelos sujeitos escolares em diferentes lugares do Brasil.

\section{CONHECENDO O CONTEXTO DE INFLUÊNCIA DA POLÍTICA PMCE}

O PMCE foi lançado em 21 de maio de 2013, como uma iniciativa interministerial, entre os Ministérios da Cultura (MinC) e da Educação (MEC). É organizado em um conjunto de parcerias, territorializações, focos de atuação, metas e ações, constituindo-se uma política de governo com a finalidade de envolver o projeto pedagógico das escolas participantes em experiências culturais em curso nas comunidades locais e nos múltiplos territórios. (BRASIL, s/d).

De forma mais específica, o PMCE foi criado com os seguintes objetivos:

enquanto outros permaneciam lá até dois anos; o membro da equipe pedagógica desempenha suas funções no turno vespertino da escola, como responsável pela coordenação pedagógica. 
I - desenvolver atividades que promovam a interlocução entre experiências culturais e artísticas locais e o projeto pedagógico das escolas públicas; II - promover, fortalecer e consolidar territórios educativos, valorizando o diálogo entre saberes comunitários e escolares, integrando na realidade escolar as potencialidades educativas do território em que a escola está inserida; III - ampliar a inserção de conteúdos artísticos que contemplem a diversidade cultural na vivência escolar, bem como o acesso a diversas formas de linguagens artísticas; IV - proporcionar o encontro da vivência escolar com as manifestações artísticas desenvolvidas fora do contexto escolar; V - promover o reconhecimento do processo educativo como construção cultural em constante formação e transformação; VI - fomentar o comprometimento de professores e alunos com os saberes culturais locais; VII integrar experiências artísticas e culturais locais no projeto político pedagógico das escolas públicas, contribuindo para a ampliação do número de agentes sociais responsáveis pela educação no território; e VIII - proporcionar aos alunos vivências artísticas e culturais promovendo a afetividade e a criatividade existentes no processo de ensino e aprendizagem. (BRASIL, 2014. Grifos meus).

Nas construções discursivas destacadas acima, o PMCE tensiona a construção do currículo em seu cotidiano, uma vez que visa articular experiências culturais locais e o projeto político pedagógico da escola (PPPe); ampliar a inserção de conteúdos artísticos na vivência escolar, além de outras finalidades nesse sentido.

A proposta do PMCE foi organizada em dez eixos temáticos que contemplam uma diversidade de objetos, os quais constituem as ações e atividades artísticas que cada eixo abrange. A proposta submetida e aprovada para a Escola Caminhos está inserida no eixo II “Criação, circulação e difusão da produção artística, sobre a qual trarei mais elementos na seção seguinte ${ }^{6}$.

Analisando os elementos que compõem as construções discursivas da política PMCE e a abordagem do Ciclo de Política (BOWE, BALL e GOLD, 1992; BALL, 1994; MAINARDES, 2006;2007; LOPES e MACEDO, 2011), identifiquei um espectro de sujeitos nacionais e internacionais compondo o seu Contexto de Influência.

Considero que a política cultural brasileira tem forte influência internacional, pois o Brasil é um país membro da Organização das Nações Unidas (ONU). Assim, sua política cultural procura

\footnotetext{
6 Para conhecer todos os eixos e seus respectivos objetos ver Brasil (s/d), acessando o endereço http://www.cultura.gov.br/.
} 
se respaldar nessa instituição. Por exemplo, o Programa Cultura Viva, o qual foi transformado em Lei de Estado, de acordo com Rollemberg (2014, p. 3), “... traz ao Brasil uma perspectiva de ampliar e aprofundar a relação da cultura e do desenvolvimento, pauta articulada pela Organização das Nações Unidas (ONU) na construção da Agenda de Desenvolvimento Sustentável pós-2015”.

A Organização das Nações Unidas para a Educação, a Ciência e a Cultura (UNESCO), em sua 32a sessão, de 1989, aprovou a "Recomendação para a Salvaguarda da Cultura Tradicional e Popular"” . Essa recomendação repercutiu em nossa política cultural mais recente, um exemplo disso foi a criação do Sistema Nacional de Cultura, anunciado no governo Lula da Silva e promulgado no governo Dilma Rousseff. Como uma das recomendações da Unesco (1989, p. 5) é a de se "constituir um Conselho Nacional sobre a cultura tradicional e popular, de base interdisciplinar, ou um organismo coordenador de caráter análogo, no qual se encontrem representados os diversos grupos de interessados". Essa recomendação é recontextualizada com a criação do Sistema Nacional de Cultura, uma política de Estado para a cultura em geral, considerada inexistente até então no Brasil.

Em relação ao PMCE, outra recomendação da Unesco que é importante destacar é a de os Estados Membros “apoiar moral e financeiramente os particulares e as instituições que promovam o estudo, a divulgação e fomentem ou sejam detentores de elementos da cultura tradicional e popular”. (UNESCO, 1989, p. 5). Esta proposição é evidente na política em tela, uma vez que busca favorecer o encontro da escola com as atividades da tradição oral e do apoio aos artistas denominados de particulares na resolução da UNESCO - que apresentem propostas de inserção cultural às escolas públicas, como pode ser visto nos objetivos do PMCE, já citados, e nos eixos dessa política.

Identifico ainda no contexto internacional que o PMCE é influenciado pela Organização dos Estados Íberoamericanos (OEI), haja vista o documento Metas do Plano Nacional de Cultura (PNC), na meta 12 afirmar:

[...] esta meta reforça o compromisso assumido pelos ministros de cultura e educação dos países membros da Organização dos Estados Íberoamericanos (OEI) na X Conferência Iberoamericana de Cultura realizada no Chile em 2007 e na conferência celebrada em Lisboa (em 2009) que culminou na criação do programa de ação das metas educativas de 2021 "Educação artística, cultura e cidadania", que preconiza que a aprendizagem em Artes é ferramenta estratégica para a plena cidadania cultural e

\footnotetext{
${ }^{7}$ Em 2015 foi lançado edital, pelo Instituto de Patrimônio Histórico e Artístico Nacional (IPHAN), para o Prêmio Boas Práticas de Salvaguarda do Patrimônio Cultural Imaterial.
} 
qualidade de ensino, assim como o fortalecimento das relações entre Cultura e educação na escola. (BRASIL, 2011, p. 36-37)

Assim, o PNC e também o PMCE são influenciados por essa Conferência e por sua instituição promotora, uma vez que essa política é um dos instrumentos para a consecução da meta citada ao buscar a inserção de conteúdos artísticos, contemplar a diversidade cultural e diversas formas de linguagens artísticas, porém, de forma recontextualizada, não sendo simplesmente implementada (BALL, 2009).

Em nível nacional foram identificadas influências dos Parâmetros Curriculares Nacionais, 1990. Nesse documento, a preocupação com a relação Educação-Cultura já estava presente ao se colocar que a escola precisaria

[..] assumir a valorização da cultura de sua própria comunidade e, ao mesmo tempo, buscar ultrapassar seus limites, propiciando às crianças pertencentes aos diferentes grupos sociais o acesso ao saber, tanto no que diz respeito aos conhecimentos socialmente relevantes da cultura brasileira no âmbito nacional e regional como no que faz parte do patrimônio universal da humanidade (BRASIL, 1997a, p.34).

Esse documento traz em seus Temas Transversais a Pluralidade Cultural. O seu texto de apresentação articula discursivamente a ideia de que ao aluno(a) "oferece oportunidades de conhecimento de suas origens como brasileiro e como participante de grupos culturais específicos". (BRASIL, 1997b, p. 39)

Ainda em nível de país, uma influência significativa para o PMCE foi a política de cultura dos governos petistas, pela qual foram criados o Programa Cultura Viva e o Programa Mais Cultura (PMC), que antecederam o PMCE. No programa de governo do então candidato Lula da Silva, de 2002, construído num espectro de siglas de diferentes ideologias, afirma-se: "A política do nosso governo estimulará a socialização dos bens culturais e contribuirá para a livre expressão de todas as manifestações no campo da cultura”. (COLIGAÇÃO LULA PRESIDENTE, 2002, p. 15).

Os programas acima citados tiveram forte influência dos movimentos sociais, haja vista entidades como a União Nacional dos Estudantes (UNE) e o Movimento dos Trabalhadores Rurais Sem-Terra (MST) estarem, juntamente com os movimentos culturais populares e de outras características, presentes nos eventos promovidos pelo Minc ou de outras instituições, discutindo e pautando suas agendas de cultura.

Tanto elementos de influências de nível nacional, quanto internacional, foram detectados na proposta do PMCE, a qual aponta para os objetos a serem contemplados nos planos elaborados 
pelas escolas, em conjunto com a iniciativa artística. Observa-se, em vários eixos e respectivas atividades, as influências de organismos internacionais como a UNESCO, nos eixos VI - Cultura afro-brasileira; VII - Culturas indígenas e VIII - Tradição oral. Nas atividades dos demais eixos podem ser percebidos elementos do Programa Cultura Viva e do PMC, no eixo III; do Instituto do Patrimônio Histórico e Artístico Nacional (IPHAN), no eixo IV.

Identifiquei semelhanças do PMCE com os seguintes programas do Minc: Livro Aberto; Brasil, Som e Imagem; Museu, Memória e Cidadania; Cultura, Educação e Cidadania; Engenho das Artes; Cultura Afro-Brasileira; Identidade e Diversidade Cultural; Monumenta; Brasil Patrimônio Cultural; Desenvolvimento da Economia da Cultura, indicando um espectro mais amplo de influências, o que nos limites deste artigo não vai ser possível abordar.

Vale salientar que o Contexto de Influência tem marcas de vários matizes, inclusive do Contexto da Prática, pois os lugares das escolas foram considerados para a construção da política PMCE, conforme o discurso de ordem estatística do acesso à cultura. De acordo com esse discurso, os sujeitos de diferentes territórios, como denomina o programa, foram alijados historicamente do acesso à cultura, necessitando de políticas de correção com a finalidade de corrigir essa defasagem em relação a outros lugares em que a população tem mais facilidades, mais recursos e, portanto, mais acesso aos bens culturais.

\section{CONHECENDO O CONTEXTO DE PRODUÇÃO DE TEXTO DA POLÍTICA PMCE}

Quanto ao Contexto de Produção de Textos do PMCE, este também é muito diverso e serve para legitimar sua proposta. Seu material é sistematizado na forma de discursos e textos oficiais, com orientações e regulamentações e outros documentos; artigos em revistas acadêmicas e de órgãos do governo, bem como matérias jornalísticas em sites oficiais e não oficiais. É por meio dessas produções que a política é representada junto às escolas e à sociedade em geral, que buscam significar sua importância justificando a sua necessidade e/ou explicando como as escolas devem lidar com o programa. Mainardes (2006, p. 52) nos lembra que tais representações podem ocorrer por meio de "textos legais oficiais e textos políticos, comentários formais ou informais sobre os textos oficiais, pronunciamentos oficiais, vídeos etc.”.

A Res. 4 - Fundo Nacional de Desenvolvimento da Educação (FNDE) de 31.03.2014, em sua ementa afirma que

Dispõe sobre a destinação de recursos financeiros, nos moldes operacionais e regulamentares do PDDE, a escolas públicas municipais, estaduais e do Distrito 
Federal, que possuam alunos matriculados no ensino fundamental e médio registrados no censo escolar do ano anterior ao do atendimento, com vistas a assegurar a realização de atividades culturais, por intermédio do Mais Cultura nas Escolas, de forma a potencializar as ações dos Programas Mais Educação e Ensino Médio Inovador. (FNDE, 2015 - grifos meus)

Essa resolução mostra que o PMCE também está imbricado com o cuidado das escolas com a gestão financeira, visto que seus recursos, vinculados ao Programa Dinheiro Direto na Escola (PDDE), devem ser administrados dentro das regras de prestação de contas, tomada de preços e aplicação definidas por rubricas específicas para cada tipo de consumo. Nesse sentido, está submetido ao gerencialismo presente nas políticas públicas, nas políticas educacionais e de currículo (BALL, 2004; 2005; 2010), nos moldes do mercado e de políticas de amplitude global, o que pode ser identificado nos textos que representam a política PMCE.

Quanto aos pronunciamentos destaquei aqueles de autoridades ligadas aos governo do PT (2003-2010; 2011-2016) e de assessores do Minc que se posicionaram sobre as políticas culturais. É central em suas construções discursivas a significação da cultura como inclusão dos sujeitos excluídos nas políticas anteriores, tendo como estratégia o reconhecimento, através do aporte de recursos, das manifestações e dos grupos populares.

Um cenário de municípios sem quaisquer meios de difundir a produção cultural e artística entre sua população e de garantir espaços de convivência com o patrimônio cultural local e universal. Este é um cenário de separação entre cultura e educação. Entre cultura e rede de proteção social. Um cenário de separação entre cultura e cidadania que foi bem auferido nos últimos números da pesquisa do IBGE. (GIL, $2007)^{8}$.

Esses dados estatísticos dão ao PMC legitimidade diante da inexistência de equipamentos culturais nos municípios. Além disso, já se apresenta nesse pronunciamento a necessidade de se juntar cultura e educação, confirmando a influência desse programa na política PMCE.

Nessa perspectiva, a correção dessas defasagens culturais, reconhecidas pelo governo como consequência do distanciamento do Estado das manifestações culturais populares e da valorização dos seus artistas, poderia se dar pela aproximação da escola com as expressões culturais do seu entorno e, ao mesmo tempo, possibilitar à escola a abertura para outros saberes no seu repertório de ensino. Foi isso o que defendeu a diretora da Secretaria de Políticas Culturais do

\footnotetext{
${ }^{8}$ Discurso do ministro no lançamento do Programa Mais Cultura, anterior ao PMCE, que considerei na pesquisa como parte do seu Contexto de Influência.
} 
Ministério da Cultura (SPC/Minc), Juana Nunes: "a escola pública é o equipamento de acesso à cultura por excelência. Com a integração da cultura, a escola vai abrir seu repertório de ensino. Sem isso, a pessoa pode passar a vida inteira com um repertório cultural fechado". (NUNES apud SANTOS, 2013).

Os eventos, tais como, conferências, encontros, reuniões etc. são outros espaços que compõem o Contexto de Produção do Texto do PMCE. Na III Conferência Nacional de Cultura, na qual foram aprovadas 64 diretrizes e 20 prioridades, em seu eixo II "produção simbólica e diversidade cultural" se tem como prioridade número 1 "Cultura e Educação" e como prioridade número 4 o "Programa Mais Cultura nas Escolas" (REVISTA DO MINC, 2013), demonstrando que a relação Educação-Cultura, objeto do PMCE, ganhou centralidade para a política de cultura e no imaginário social dos representantes dos povos e grupos culturais presentes naquele evento.

Na descrição da prioridade número 1 do eixo 2, encontra-se o seguinte trecho:

Reconhecer as práticas culturais como formadoras de subjetividades e coletividades, valorizando os conhecimentos dos povos tradicionais, bem como das manifestações artísticas/culturais contemporâneas favorecendo o intercâmbio entre o ensino formal e não formal (REVISTA DO MINC, 2013, p. 55).

Essa proposta aprovada durante a III Conferência Nacional de Cultura legitima as proposições do PMCE, uma vez que esse programa tem como finalidade promover o encontro das escolas contempladas com as experiências culturais das comunidades e territórios. A defesa do programa fica mais evidente na redação da prioridade 4 desse mesmo eixo:

Garantir a implementação, ampliação, desenvolvimento, consolidação, avaliação e gestão, de forma compartilhada, do "Programa Mais Cultura nas Escolas" e torná-lo uma política de Estado, ampliando as ações do programa para além do "Mais Educação" (a fim de atender às unidades escolares com diferentes avaliações do IDEB e em distintos territórios), bem como garantir a promoção de experiências educacionais inovadoras e a remuneração dos educadores de acordo com o exercício de suas funções, buscando a implementação do programa em 100\% das escolas públicas, inclusive as de educação integral, contando para tanto, com o fortalecimento da articulação entre os entes federados, a melhoria e adequação da estrutura física das instituições escolares e a capacitação da comunidade escolar. (REVISTA DO MINC, 2013, p. 56. Destaques do original).

Essa construção discursiva se destaca pelo fato de que, apesar de defenderem o PMCE, os participantes do evento buscam a desconstrução dessa política na forma como foi apresentada, defendendo-a em outros moldes, a fim de torná-la mais democrática e sustentável, para contemplar 
escolas e territórios excluídos e garantir sua transformação em política de Estado, além de buscar envolver estados e municípios.

Esse conjunto de representações que legitimam o PMCE mostram que foram colocados às escolas novos desafios na relação com o seu entorno e com a construção cotidiana do currículo, haja vista essa política trazer um sentido de educação de qualidade que procura se hegemonizar pelo discurso da necessidade de parcerias, acompanhamento, inserção de novos conteúdos, prestação de contas e atendimento de anseios da comunidade escolar e local. Dessa forma, o currículo vai se construindo no dia a dia da escola, numa recontextualização por hibridismo no Contexto da Prática, em um processo que Ball chamou, mais recentemente, de atuação da política.

\section{A POLÍTICA PMCE NO CONTEXTO DA PRÁTICA: SUJEITOS EM ATUAÇÃO}

Para compreendermos a importância do Contexto da Prática no Ciclo de Política, vale salientar que a escola historicamente foi vista como o lugar em que as políticas são implementadas por uma imposição do Estado, portanto, desprovida de ações de produção de políticas, limitando-se à sua implementação. Em sendo este espaço-tempo parte de um ciclo da política, esse contexto passa a ser considerado também como produtor na relação com os outros contextos, superando assim uma compreensão do tipo top down ou do tipo down top, na análise de políticas (LOPES e MACEDO, 2011).

Para Mainardes (2006, p. 53),

De acordo com Ball e Bowe (Bowe et al., 1992), o contexto da prática é onde a política está sujeita à interpretação e recriação e onde a política produz efeitos e consequências que podem representar mudanças e transformações significativas na política original.

Assim, na análise da política no Contexto da Prática é importante se deter naquilo que os sujeitos representam em sua atuação (BALL; MAGUIRE; BRAUN, 2016). Por isso, busquei interpelar aqueles que considerei como sendo os sujeitos mais específicos na atuação da política programas/projetos no espaço-tempo da escola, fazendo registros de conversas desinteressadas, entrevistando e analisando documentos para fins de compreender, mesmo que provisória e contingencialmente, o Contexto da Prática da política em tela, que neste texto optei apenas pelo PMCE.

O PMCE é compreendido pelos sujeitos escolares, incluindo o parceiro artístico da escola, de diferentes maneiras, com isso, em suas entrevistas foi possível detectar diferentes significados 
sobre essa política. A opção para este artigo foi trabalhar com apenas um sujeito de cada categoria: professor, aluno, parceiro artístico e um membro da equipe pedagógica da escola. Dadas as minhas finalidades aqui, selecionei apenas alguns fragmentos de suas falas para fins de análise, dando maior ênfase à entrevista feita com o parceiro artístico, pelo seu papel de maestro da proposta.

Um professor entrevistado, fazendo inicialmente uma ressalva, devido a sua área de atuação disciplinar, afirma sobre o PMCE:

- Bom, devido a minha área, pelo que eu tenho visto, é um programa relacionado à cultura, que é mais cultura, mais cultura na escola. (Professor)

Na fala do professor o PMCE é significado como uma política que traz um repertório cultural para ser somado a um acervo que já existe na escola. Daí a repetição mais cultura, mais cultura na escola, o que não se constitui uma referência simplesmente ao nome do programa/projeto, mas a uma ideia de adição, o que só foi possível perceber devido o pesquisador estar presente por meio da observação participante, pois em várias oportunidades testemunhei discussões sobre as necessidades dos alunos(as) aprenderem mais, lerem mais, estudarem mais etc.

Já um aluno, que participou do PMCE, ao ser indagado sobre o que seria para ele essa política, respondeu:

- É um projeto voltado para a cultura do nosso povo. É um projeto para cantar. (aluno NR)

Essa compreensão mostra que o aluno significa esse programa/projeto de um modo muito objetivo, o que pode ter sido influenciado pela forma como a proposta aprovada para a Escola Caminhos é enunciada em seu título: “Canto do Povo do Meu Lugar" (ver figura 1) e pelas atividades das quais participou. Conforme entrevista do parceiro foi possível passar a biografia de seis artistas, sendo um da comunidade, um do estado do RN e os demais do Nordeste e interpretar algumas de suas músicas. 


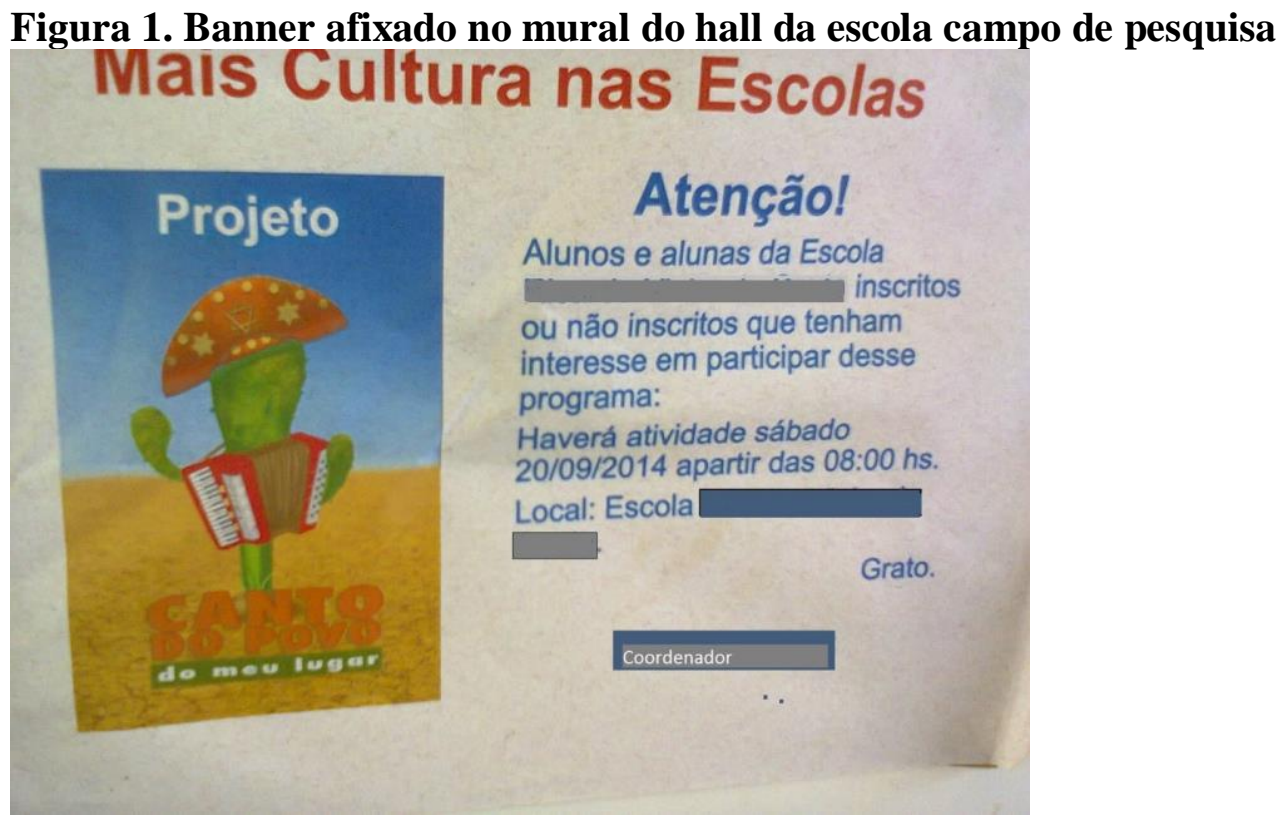

Fonte: pesquisa do autor.

O parceiro artístico, por sua vez, traz a influência do seu gosto musical para a significação do PMCE e o desejo de reverter a propagação de um estilo de música que ganhou a mídia e que, no seu entendimento, está mais presente entre os jovens do que a música regional, representada por artistas como Luiz Gonzaga, por exemplo. Ao se reportar ao que espera da sua atuação nessa política, revelou:

- Se realmente não muda essa música que está aí desviando esse menino. Quem sabe se ele não vai ter um pensamento mais luizgonzaguiano 9 . Quem sabe se eu não vou descobrir nele um talento, desse e de outros meninos dentro do estúdio, que é também um dos objetivos desse programa. (Parceiro Artístico)

Em sua fala o parceiro artístico significa o programa/projeto como um espaço-tempo capaz de trazer mais qualidade musical para os participantes, pelo sonho que tem de enfrentar o que ele considera música de baixa qualidade, em favor de um repertório regional, enfatizando a possibilidade dos sujeitos adquirirem um gosto diferenciado para a música, o que chamou de "um pensamento mais luizgonzaguiano". Outra atribuição de forte significado é o de emancipação, ao sugerir que outros ritmos musicais desviam os jovens do que considera a boa música, para ele a música de raiz nordestina.

\footnotetext{
${ }^{9}$ A expressão refere-se a Luiz Gonzaga, considerado o Rei do Baião pela obra que produziu, principalmente no estilo forró e canções como Asa Branca e Meu Último Pau de Arara, que retrataram a cultura e a problemática social do Sertão Nordestino.
} 
Ao entrevistar um membro da equipe pedagógica (MEP), uma questão que foi colocada sobre a continuidade desse programa, esse justificou que deveria haver a continuidade dessa política acrescentando:

- Nós temos na nossa escola muitos artistas, eles deveriam ser bem trabalhados dentro dessa área da cultura (MEP).

De acordo com a compreensão do Membro da Equipe Pedagógica, o PMCE é significado como a possibilidade do desenvolvimento do potencial artístico dos alunos(as) e, nesse sentido, deveria ter continuidade na escola.

Outra questão que chamou a atenção foi o potencial de influência das famílias na política programas/projetos. Em relação ao PMCE constatei isso na entrevista com o Parceiro Artístico, quando afirmou que:

- Vamos reunir os pais uma tarde; vamos colocar os meninos para cantar, para mostrar: olhe o projeto é esse! Antes da gente entrar no estúdio a gente já vai ter isso. (Parceiro Artístico).

À família é dada uma grande importância, pois mesmo quando esta não participa diretamente da política, sua influência se faz presente, haja vista ser direcionada a ela uma espécie de prestação de contas na forma de uma encenação, como resultado do trabalho, antes da reprodução do CD (entrar no estúdio) que se constituiria no resultado do trabalho. Tal preocupação se configura em mais uma forma de influência da cultura da performatividade, bem como da accountability, presentes na arquitetura da política programas/projetos em geral e da política do PMCE em particular.

Um problema alegado por alguns dos sujeitos da atuação da política PMCE, foi o repasse dos recursos

- Ele trabalhou com alguns alunos, veio até o recurso para comprar os equipamentos, foi comprado caixa de som, foi comprado um tripé para caixa de som, foi comprado microfone, alguns materiais para dar apoio ao projeto, mas infelizmente os recursos não estão vindo. (MEP)

A falta de recursos é muito frequente para a continuidade das políticas públicas em nosso país, especialmente as da área da educação. No caso do PMCE na Escola Campo de Pesquisa, trouxe dificuldades para o desenvolvimento dos trabalhos, inclusive impossibilitando o resultado final previsto na proposta da escola: a gravação do CD com as músicas cantadas pelos alunos(as). 
Assim, nesse conjunto de interações que os sujeitos em atuação na política PMCE articula no Contexto da Prática, vão sendo tecidas suas tramas e estabelecendo, com os demais contextos, relações próprias do ciclo da política em tela.

Nessa perspectiva, a cultura se constituiu como central para a circularidade de sentidos de qualidade, emancipação, complementaridade, oportunidade, bem como para o processo de recontextualização dessa política, o qual se deu/se dá por hibridismo (LOPES, 2008). Por isso, apesar de ser crivada com observações críticas por professores(as), membro da equipe pedagógica e alunos(as), na Escola Caminhos se requer a sua continuidade.

\section{CONSIDERAÇÕES FINAIS}

O programa PMCE é mais uma política no conjunto das Políticas Mais, que se constituíram uma espécie de carro-chefe nos governos Lula Da Silva e Dilma Rousseff. Em seu Contexto de Produção de Texto percebi as múltiplas relações com instituições nacionais e internacionais, bem como com movimentos sociais, especialmente ligados à cultura, além de partidos políticos, instituições governamentais e não-governamentais.

Isso possibilitou perceber também a configuração do seu Contexto de Influência e fazer inferências quanto às disputas de sentido que estão envolvidas nessa política, não somente em nível macro, mas também em nível micro, no local, mostrando que o Contexto da Prática não se constitui, no ciclo da política, um espaço-tempo apenas de implementação. Por exemplo, percebi que há na significação dessa política, uma disputa de sentido de música de qualidade, em função do seu exterior constitutivo, a música que é significada como de "má qualidade"10.

O PMCE é significado também pela possibilidade de se constituir um espaço-tempo de descoberta de talentos. Essa significação dada ao programa reforça a cultura da performatividade, o que é muito comum nas políticas de um modo geral e nas políticas de educação em particular.

Dois aspectos foram muito importantes na apreensão dessa política no Contexto da Prática: o conhecimento da comunidade e da própria escola, por meio da observação participante e, por meio da análise de documentos, o conhecimento do material que compõe essa política em nível

\footnotetext{
${ }^{10}$ Devido às especificidades da pesquisa, não explorei junto ao parceiro artístico os significantes "música de qualidade e música de baixa qualidade" inferidos da entrevista. Mas, independentemente disso, considero-os como significantes vazios, conforme Laclau (2011).
} 
nacional e a proposta sistematizada em nível local. Com isso identifiquei tentativas de fixação de sentidos nos diferentes contextos do ciclo da política PMCE.

Para finalizar recorro a Lopes (2015, p. 457): "sempre diferentes discursos - mercado, emancipação, cidadania, mundo em mudança, qualidade de ensino, adequação à globalização, saberes universais, conteúdos básicos, justiça social, igualdade, diferença - estarão disputando a significação do que vem a ser currículo e produzindo significações imprevistas”. É isso que ocorre na construção do currículo na Escola Caminhos e a política PMCE deu sua contribuição nessa disputa, pois, a música se por um lado embalou sonhos e projetos, por outro, constituiu-se uma arena de disputa de sentidos, sejam estes de qualidade, de formação, de regionalização e de participação, entre outros tantos possíveis. 


\section{REFERÊNCIAS BIBLIOGRÁFICAS}

BALL, S. Education reform: a critical and post-structural approach. Beckingham: Open University Press, 1994.

. Performatividades e Fabricações na Economia Educacional: rumo a uma sociedade performativa. Educação e Realidade. v. 35, n. 2, maio/ago. 2010. p. 37-55. Disponível em: http://seer.ufrgs.br/index.php/educacaoerealidade/ article/view/15865/9445.

. Entrevista com Stephen J. Ball: um diálogo sobre justiça social, pesquisa e política educacional. Educação e Sociedade. Campinas, vol. 30, n. 106, p. 303-318, jan./abr. 2009. Disponível em: http://www.cedes.unicamp.br.

Profissionalismo, Gerencialismo e Performatividade. Cadernos de Pesquisa, v. 35, n. 126, p. 539-564, set./dez. 2005. Disponível em: http://www.scielo.br/pdf/cp/v35n126/a02n126.pdf.

. Performatividade, privatização e o pós-Estado do bem-estar. Educação e Sociedade, Campinas, vol. 25, n. 89, p. 1105-1126, Set./Dez. 2004. Disponível em: http://www.cedes.unicamp.br.

; MAGUIRE, M; BRAUN, A. Como as escolas fazem as políticas: atuação em escolas secundárias. Trad. Janete Bridon. Ponta Grossa: UEPG, 2016. 220 p.

BOWE, R.; BALL, S.; GOLD, A. Reforming education \& changing schools: case studies in policy sociology. London: Routledge, 1992.

BRASIL. Ministério da Educação e do Desporto/Ministério da Cultura. Programa Mais Cultura nas Escolas: manual de desenvolvimento das atividades. Brasília: MEC/MINC, s/d.

Ministério da Educação e do Desporto. Secretaria de Educação Fundamental. Parâmetros Curriculares Nacionais: Língua Portuguesa. Brasília, 1997a. 144 p.

. Ministério da Educação e do Desporto. Secretaria de Educação Fundamental. Parâmetros Curriculares Nacionais: Pluralidade Cultural, Orientação Sexual. Brasília, 1997b. 164 p.

Metas do Plano Nacional de Cultura. Brasília: Ministério da Cultura, 2011. Disponível em: http://www.cultura.gov.br/documents/10883/11294/METAS_PNC_final.pdf/

Diretoria de Currículos e Educação Integral. Manual Operacional de Educação Integral. Brasília: MEC/SEB, 2014.

COLIGAÇÃO Lula Presidente. Programa de Governo. Comitê Lula Presidente: São Paulo, 2002. Disponível em: http://novo.fpabramo.org.br/uploads/programagoverno.pdf.

FNDE. RESOLUÇÃO 4/2014. Dispõe sobre a destinação de recursos financeiros, nos moldes operacionais e regulamentares do PDDE. Brasília: FNDE Legis, 2015 Disponível em: http://www.fnde.gov.br/fnde/legislacao/resolucoes/item/5350-resolução-cd-fnde-no -4-de-31-de-março-de-2014.

GEERTZ, Clifford. A Interpretação das Culturas. Rio de Janeiro: LTC, 2008.

GIL, Gilberto. Discurso do ministro Gilberto Gil no lançamento do Programa Mais Cultura. Brasília-DF, 04 out. 2007. Disponível em: http://www.cultura.gov.br/discursos/asset_publisher/DmSRak0YtQfY/content/discurso-doministro-gilberto-gil-na-cerimonia-de-lancamento-do-programa-mais-cultura-.

LACLAU, Ernesto. Emancipação e Diferença. Rio de Janeiro: EdUERJ, 2011. 222 p.

LOPES, A. Políticas de integração curricular. Rio de Janeiro: EdUERJ, 2008. 184 p.

. Por um currículo sem fundamentos. Linhas Críticas, Brasília, DF, v.21, n.45, p. 445-466, mai./ago. 2015. Disponível em: http://periodicos.unb.br/index. php/linhascriticas/article/view/16735/11881.

; MACEDO, E. Teorias de Currículo. São Paulo: Cortez, 2011

MAINARDES, Jefferson. Abordagem do Ciclo de Políticas: uma contribuição para a análise de políticas educacionais. Educação e Sociedade. Campinas, vol. 27, n. 94, p. 47-69, jan./abr. 2006. Disponível em: http://www.cedes.unicamp.br.

Reinterpretando os Ciclos de Aprendizagem. São Paulo: Cortez, 2007.

MAINARDES, Jefferson. e STREMEL, Silvana. Teoria de Basil Bernstein e Algumas de suas Contribuições para as Pesquisas sobre Políticas Educacionais e Curriculares. in: Revista Teias v. 11 • n. 22 • p. 31-54. maio/agosto 2010. 
REVISTA do Minc. Íntegra das propostas aprovadas. Revista do Minc. 3 ed. Dez. 2013.

ROLLEMBERG, Márcia. Editorial. Revista do Minc. 5 ed. Dez. 2014 . Disponível em: http://www.cultura.gov.br/publicacoes//asset_publisher/xadX3oKvTsLq/content/revista-do-mi-1/10883

SANTOS, Carla. Integração da cultura à educação será um salto para o governo Dilma. Portal Vermelho. 25 jan.2013. Disponível em: http://www.vermelho.org.br/noticia/204420-11.

TURA, Maria L. R. et al. Olhares etnográficos: investigando a produção de currículos na escola. In: FERRAÇO, C. E. GABRIEL, C. T. AMORIM, A. C. (orgs.). Políticas de Currículo e Escola. Campinas: FE/UNICAMP, 2012. book GT Currículo). p 103-118.

; SILVA, Sofia Marques da. Etnografia da prática pedagógica em contextos de multiculturalidade: o caso de uma Escola do Rio de Janeiro e de uma Escola do Porto. In: TURA, Maria de Lourdes Rangel; LEITE, Carlinda (Org.). Questões de currículo e trabalho docente. Rio de Janeiro: Quartet/ FAPERJ, 2010, p. 71-105.

O olhar que não quer ver: histórias da escola. Petrópolis: Vozes, 2000.

UNESCO. Recomendação para a Salvaguarda da Cultura Tradicional e Popular. (trad. Departamento de Patrimônio Imaterial / Instituto dos Museus e da Conservação). UNESCO: Paris, 1989. Disponível em: http://portal.iphan.gov.br/portal/montarPaginaSecao.do?id=12372\&sigla=Legislacao\&retorno=paginaLegislacao.

\section{Referências Musicais}

ONE MORE THOUGHT LUIZGONZAGUIANO: music and dreams of a rural community school

UN PENSAMIENTO MÁS LUIZGONZAGUIANO: música y sueños de una escuela de comunidad rural 


\section{RESUMO}

Este artigo analisa a política Programa Mais Cultura nas Escolas no Contexto da Prática, tendo como lócus uma escola de comunidade rural. Esta política faz parte de um pacote que o autor denominou de Políticas Mais, as quais se tornaram uma espécie de carro-chefe dos Governos Lula da Silva (2003-2010) e Dilma Roussef (2011-2016). Sob a análise do Ciclo de Política, constatou-se que a proposta local de se trabalhar com música, embalou sonhos e projetos entre os sujeitos da escola, que em seu conjunto tinham como objetivos revelarem talentos e mudanças no gosto musical dos jovens participantes. Dessa forma, a proposta constituiu-se uma arena de disputa de sentidos do que seja a música de boa qualidade, além de uma diversidade de outros sentidos.

Palavras-chave: Música; Currículo; Escola

\section{ABSTRACT}

This paper analyzes the Program More Culture in Schools policy in the practice context, having a rural community school as locus. This policy is part of a whole that the author nominated as More Policies, it have become a kind of a flagship of Lula da Silva (2003-2010 and Dilma's Roussef (2011-2016) government. Under the analysis of the Policy Cycle, it was found that the local proposal to work with music, aroused dreams and projects among the school members, which together had the objective to discover talents and changes in the musical interest of the young participants. Therefore, the proposal constituted an arena of dispute meanings about what good/qualified music is, besides a diversity of other senses.

Keywords: Music; Curriculum; School

\section{RESUMEN}

En este artículo se analiza la política Programa Más Cultura en las Escuelas en el contexto de la práctica, teniendo como locus una escuela de comunidad rural. Esta política es parte de un conjunto que el autor denomina de Políticas Más, que se han convertido en una especie de buque insignia del Gobierno Lula da Silva (2003-2010) y Dilma Roussef (2011-2016). En el marco del análisis del Ciclo de Política, se descubre que la propuesta local para trabajar con música, ha embalado sueños y proyectos entre los sujetos de la escuela, que en equipo tenían los objetivos de revelaren talentos y cambios en gusto musical de los jóvenes participantes. De esa manera, la propuesta constituyó una arena de disputa de sentidos do que es la música de buena calidad, además de una diversidad de otros sentidos.

Palabras-clave: Música; Currículum escolar; Escuela. 